This item was submitted to Loughborough's Research Repository by the author.

Items in Figshare are protected by copyright, with all rights reserved, unless otherwise indicated.

\title{
The influence of touchdown parameters on the performance of a high jumper
}

PLEASE CITE THE PUBLISHED VERSION

PUBLISHER

(c) Human Kinetics, Inc.

VERSION

AM (Accepted Manuscript)

LICENCE

CC BY-NC-ND 4.0

REPOSITORY RECORD

Grieg, Matthew P., and Maurice R. Yeadon. 2019. "The Influence of Touchdown Parameters on the Performance of a High Jumper”. figshare. https://hdl.handle.net/2134/6143. 
This item was submitted to Loughborough's Institutional Repository (https://dspace.lboro.ac.uk/) by the author and is made available under the following Creative Commons Licence conditions.

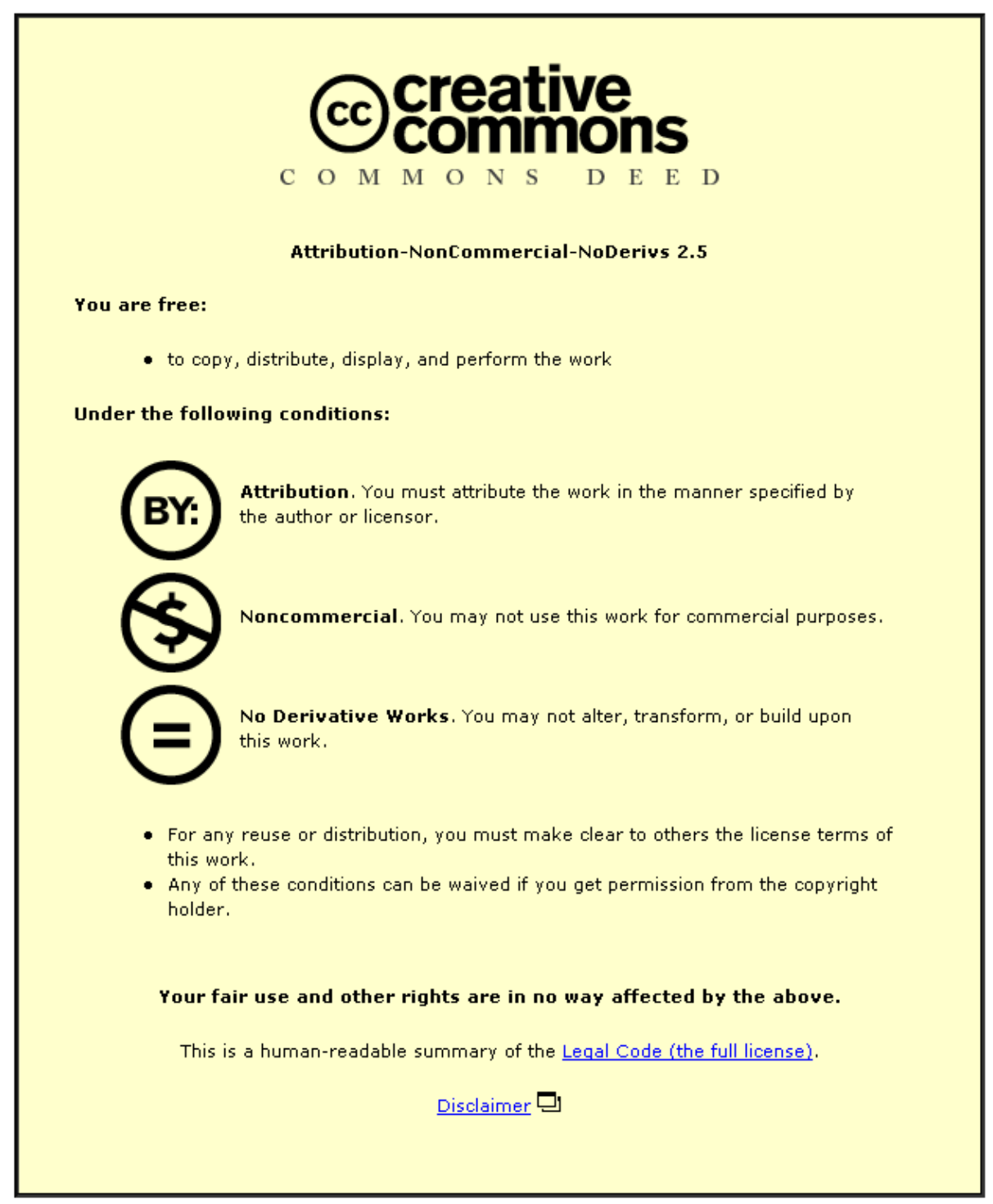

For the full text of this licence, please go to: http://creativecommons.org/licenses/by-nc-nd/2.5/ 


\title{
The influence of touchdown parameters on the performance of a high jumper
}

\author{
Matthew P. Greig and Maurice R. Yeadon
}

\author{
M. P. Greig is with the Sports Biomechanics Laboratory, Department of Sports Science, \\ University of Hull, HU6 7RX, UK \\ M. R. Yeadon is with the Sports Biomechanics Laboratory, Department of Sports Science, \\ Loughborough University, Leics. LE11 3TU, UK
}

\begin{abstract}
In order to maximise the mass centre vertical velocity at toe-off and thereby jump height the approach parameters in high jumping must be optimised. The present study aimed to determine the influence on jump height of the approach speed, the leg plant angle and the knee angle at touchdown. Sixteen trials by an elite male high jumper were recorded in a single training session. Direct intervention was used to induce a change in technique so that a greater range in approach speed was obtained than was observed in competition. The optimum approach was shown to be fast $\left(7.0 \mathrm{~m} . \mathrm{s}^{-1}\right)$ with the leg planted away from the vertical $\left(34^{\circ}\right)$ and with minimum knee flexion. A regression equation was obtained which was able to account for $79 \%$ of the observed variation in jump height. Jump height performance was shown to be most sensitive to changes in leg plant angle and knee angle at touchdown.
\end{abstract}

Keywords: high jumping, approach, experimental, performance

\section{Introduction}

The high jump comprises three distinct phases: the approach run to the bar, the plant and takeoff, and the flight phase and bar clearance. Dapena (1988) observed that the purpose of the approach is to set the appropriate conditions for the beginning of the takeoff phase. The takeoff phase is defined as the period of time between the instant when the takeoff foot first touches the ground (touchdown or plant) and the instant when it loses contact with the ground (toe-off). The peak height of the mass centre during the flight over the bar is dependent on the height and vertical velocity of the mass centre at toe-off. The mass centre height at toe-off is largely dependent on the standing height of the athlete and so the high jumper should therefore strive to maximise the vertical mass centre velocity at toe-off.

In order to maximise the mass centre vertical velocity at toe-off the approach parameters must be optimised. Alexander (1990) used a two segment simulation model with a single muscle to show that jump height was maximised at intermediate values of approach speed and plant angle. However the optimum technique determined by Alexander's model was not specific to any athlete. Dapena et al. (1990) collected data on 77 elite high jumpers in competition. In contrast to the quadratic type of relationship between approach speed and jump height for a single athlete obtained by Alexander, Dapena et al. found a linear relationship between approach speed and jump height when using the best jump of each athlete. The faster approach speeds used by the stronger jumpers were shown to produce greater jump heights. However such a study on many athletes is limited in what can be stated regarding any one individual athlete. Indeed no optimum values can be given for individual athletes based on data from a single jump by each athlete.

In contrast to the approach used by Dapena, data collected on multiple performances by a single athlete may give insight into an individual's optimum technique. In a high jumping competition a single athlete will perform typically about eight jumps and there will be only small ranges in the approach parameters such as run-up speed. Furthermore, if the athlete enters the 
competition early (at a low bar height) then not all of the jumps may be maximum efforts. Each of these factors reduces the likelihood of obtaining a result of statistical significance using data collected in competition.

The training environment provides greater experimental control than competition since a greater amount and a greater range of data may be collected. Direct intervention may be used with the cooperation of the athlete in the training environment so that the technique may be manipulated in some way. The subsequent influence on jump height performance may then be investigated. This form of intervention is generally not possible during a competition. However, Hay (1985) suggested that athletes may perform differently in training than they do in competition. Furthermore, Dapena et al. (1990) held the opinion that a high jumper cannot make many maximum effort jumps in a single day.

Many coaches advocate a fast and low approach to the bar. Woicik (1983) stated that the athlete should lower the mass centre in such a way as to maintain horizontal velocity. However Dapena (1988) considered that the athlete may be too fast as a result of excessive approach speed and too low as a result of an excessive plant angle. Many coaches describe a "buckling" of the takeoff leg if the jumper exceeds the optimum approach speed or plant angle. So what is the optimum approach speed and plant angle for an elite high jumper, and how does jump height vary away from optimum technique? The sensitivity of jump height to changes in parameters such as approach speed may have important coaching implications.

The purpose of the present study was to determine how the maximum height of the mass centre during flight is dependent on the horizontal speed of the mass centre, the plant angle, and the knee angle of the takeoff leg at touchdown for an elite high jumper and to consider whether these experimental relationships are consistent with the theoretical results of Alexander (1990).

\section{Method}

The subject was an elite male high jumper of height $1.96 \mathrm{~m}$ and mass $78.7 \mathrm{~kg}$ with a personal best competition performance of $2.32 \mathrm{~m}$. Segmental inertia parameters of the subject were calculated from 95 anthropometric measurements using the mathematical inertia model of Yeadon (1990b). The data collection was carried out during a training session at the Loughborough University athletics track. The approach speed was varied by gradually increasing the length of the approach and by instructing the athlete to vary the pace of the approach. As the length of the approach increased the bar was raised to give the athlete a realistic target and to make the task more familiar.

Sixteen jumps were recorded using a Locam II $16 \mathrm{~mm}$ high speed cine camera operating at a nominal rate of 200 frames per second and a Panasonic F15 SVHS video camera with a Panasonic AG-5475 video recorder operating at 50 fields per second . The actual frame rate of the cine camera was determined by recording a millisecond timing device before and after the jumps session. The cine camera axis was placed perpendicular to the final direction of the approach while the video camera viewed the final part of the approach from behind the athlete. The image analysis of each jump started prior to the penultimate foot contact of the approach and continued until the flight path of the mass centre had passed its peak.

Prior to digitising the jump sequences, 18 control points were digitised to allow the calibration of a volume measuring $6 \mathrm{~m} \times 4 \mathrm{~m} \times 2.4 \mathrm{~m}$ using the Direct Linear Transformation (DLT) method (Karara, 1980). In the movement fields 15 body landmarks were identified and digitised for each camera view. The three-dimensional coordinates of the wrists, elbows, shoulders, hips, knees, ankles, toes and the mid-head were then obtained using the DLT reconstruction procedure. Reconstruction error estimates were obtained for the threedimensional coordinates of the calibration points. The precision in the reconstruction of the three-dimensional coordinates of the body landmarks was estimated from the residuals in the 
DLT reconstruction as described in Yeadon and King (1999). Whole body mass centre location was calculated from the coordinates of the body landmarks and the segmental masses and relative mass centre locations. Orientation and configuration angles were calculated using the methods of Yeadon (1990a). No data smoothing was used at any stage of the calculations.

Interpolating quintic splines (Wood and Jennings, 1979) were fitted to the digitised coordinate data to allow the estimation of data values at $0.005 \mathrm{~s}$ intervals for both video and film. In order to determine the synchronisation offset between the data obtained from the two cameras, different offsets at intervals of $0.001 \mathrm{~s}$ were used. For each time offset the corresponding root mean square distance of the 15 body landmarks from the four DLT planes over all film frames was calculated. The synchronisation offset that minimised the root mean square distance was used (Yeadon and King, 1999).

Four performance variables were identified. The jump height h was defined as the peak height reached by the whole body mass centre of the athlete, irrespective of its location relative to the high jump bar. The approach speed $\mathrm{v}$ was defined as the average horizontal speed of the mass centre from the penultimate touchdown to the final touchdown. The leg plant angle $\phi$ and the knee angle $\gamma$ were defined at touchdown as shown in Figure 1.

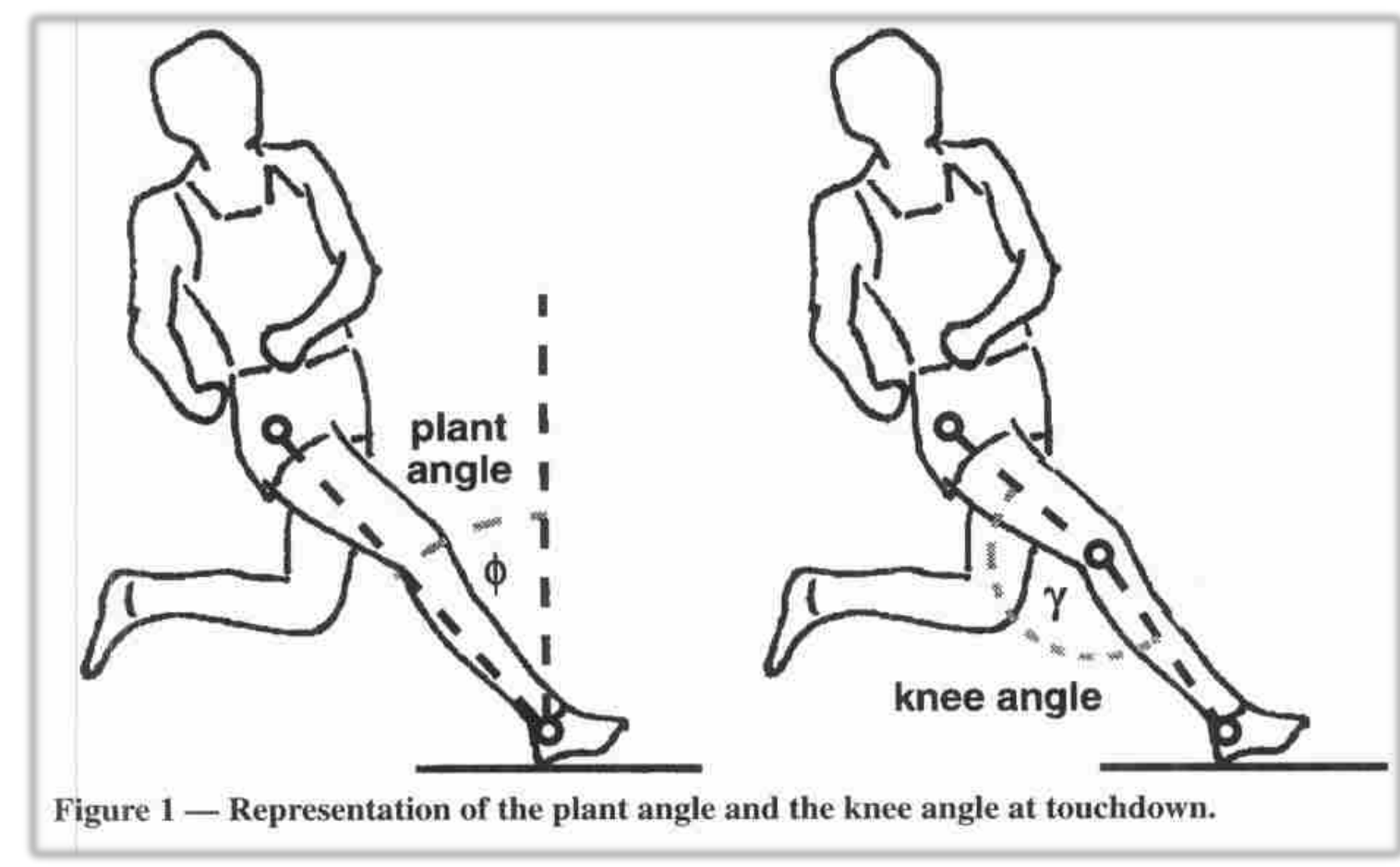

The influence on jump height of each of the approach parameters was considered. Evidence of both linear and quadratic correlation with jump height was investigated for each approach parameter. The inter-relationships of the approach parameters were also considered. The interdependence of approach parameters was accounted for by using residual values obtained by linear detrending with respect to each of the approach parameters. This is the procedure used repeatedly in stepwise regression (Draper and Smith, 1981). For example, residual values $h_{\phi}$ were obtained by calculating the difference between the recorded value of $h$ and the predicted value obtained from the linear regression equation relating $\mathrm{h}$ to $\phi$. Similarly the residual values for $\mathrm{v}_{\phi}, \mathrm{v}_{\phi}^{2}, \gamma_{\phi}$ and $\gamma_{\phi}^{2}$ were determined. $\mathrm{h}_{\phi}$ was regressed against $\mathrm{v}_{\phi}$ and $\mathrm{v}_{\phi}{ }_{\phi}$ and also against $\gamma_{\phi}$ and $\gamma_{\phi}^{2}$ to reconsider the quadratic relationships between jump height and approach variables. Variables were also linearly detrended with respect to $\mathrm{v}$ and $\gamma$ and regressions of $h_{v}$ and $h_{\gamma}$ considered. No 
residual values in $\mathrm{v}_{\gamma}$ or $\gamma_{\mathrm{v}}$ were used due to the strong linear correlation between $\mathrm{v}$ and $\gamma$. The sensitivity of jump height to changes in the approach parameters that might be expected in competition was determined using the statistical relationships derived from the training data.

\section{Results}

The actual frame rate of the cine camera both before and after the jumps session was 198.0 Hz. It was therefore assumed that the frame rate had remained constant throughout the data collection. The reconstruction error estimate of the three-dimensional coordinates of the calibration points was $0.009 \mathrm{~m}$. The precision estimate of the locations of the digitised body landmarks was $0.026 \mathrm{~m}$.

Linear regressions of jump height against each of the approach parameters produced the following equations:

(1) $\mathrm{h}=1.6532+0.07864 \mathrm{v}$

$$
\begin{array}{llll}
\text { s.e. }=0.027 \mathrm{~m} & \mathrm{r}^{2}=0.647 & \mathrm{p}_{\mathrm{c}}<0.001 & \mathrm{p}_{\mathrm{v}}<0.001 \\
\text { s.e. }=0.033 \mathrm{~m} & \mathrm{r}^{2}=0.468 & \mathrm{p}_{\mathrm{c}}<0.001 & \mathrm{p}_{\phi}=0.003 \\
\text { s.e. }=0.024 \mathrm{~m} & \mathrm{r}^{2}=0.715 & \mathrm{p}_{\mathrm{c}}<0.001 & \mathrm{p}_{\gamma}<0.001
\end{array}
$$

(2) $\mathrm{h}=1.6127+0.01643 \phi$$$
\text { (3) } \mathrm{h}=1.0493+0.00659 \gamma
$$

where s.e. is the standard error of fit, $r^{2}$ is the coefficient of determination, $p_{c}$ is the statistical significance of the constant term and $\mathrm{p}_{\mathrm{v}}$ is the significance level of the term in $\mathrm{v}$ (similarly for $\phi$ and $\gamma$ ).

Quadratic regression equations were derived to investigate the non-linear relationships presented by Alexander (1990).

(4) $\mathrm{h}=-0.836+0.8449 \mathrm{v}-0.05871 \mathrm{v}^{2} \quad$ s.e. $=0.024 \mathrm{~m} \quad \mathrm{r}^{2}=0.734$

$$
\mathrm{p}_{\mathrm{c}}=0.502 \quad \mathrm{p}_{\mathrm{v}}=0.041 \quad \mathrm{p}_{\mathrm{v}^{2}}=0.060
$$

(5) $\mathrm{h}=-1.112+0.1801 \phi-0.00245 \phi^{2} \quad$ s.e. $=0.032 \mathrm{~m} \quad \mathrm{r}^{2}=0.542$

$$
\text { (6) } \mathrm{h}=-3.964+0.0665 \gamma-0.000178 \gamma^{2} \quad \text { s.e. }=0.025 \mathrm{~m} \quad \mathrm{r}^{2}=0.730 \quad \mathrm{p}^{2}=0.173
$$

The coefficients of the quadratic terms all had corresponding $p$ values greater than $p=0.06$ indicating that there was no strong evidence of a quadratic relationship. Figures 2-4 show the influence of each approach parameter on jump height. Based on the previous regressions the data points are fitted with a linear function in each case. 


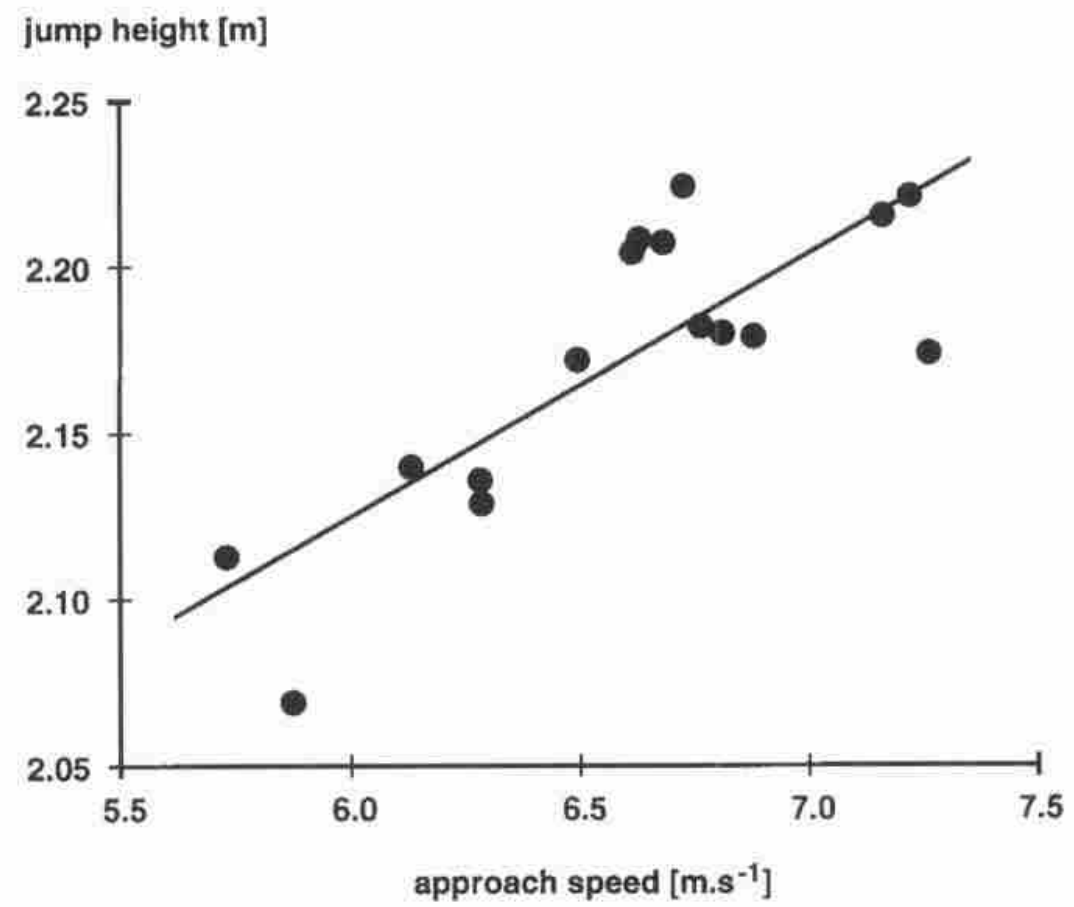

Figure 2 - The influence of approach speed on jump height.

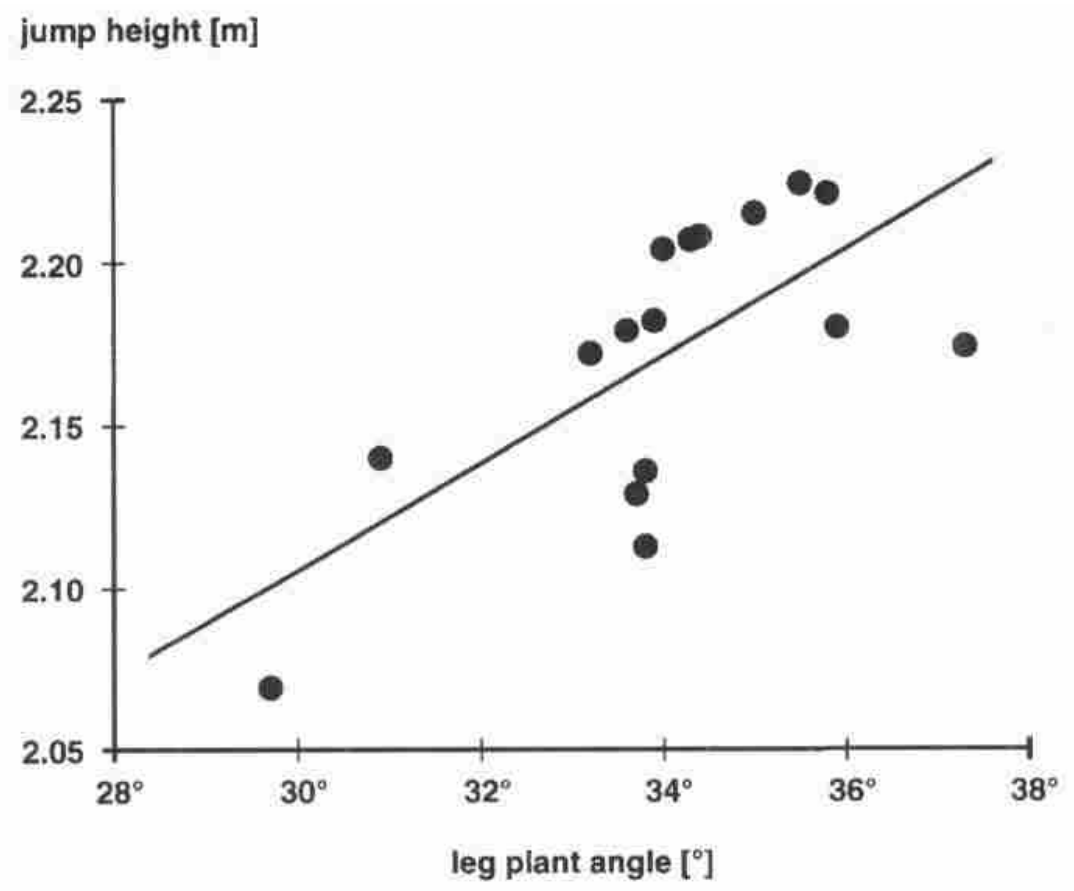

Figure 3 - The influence of leg plant angle on jump height. 


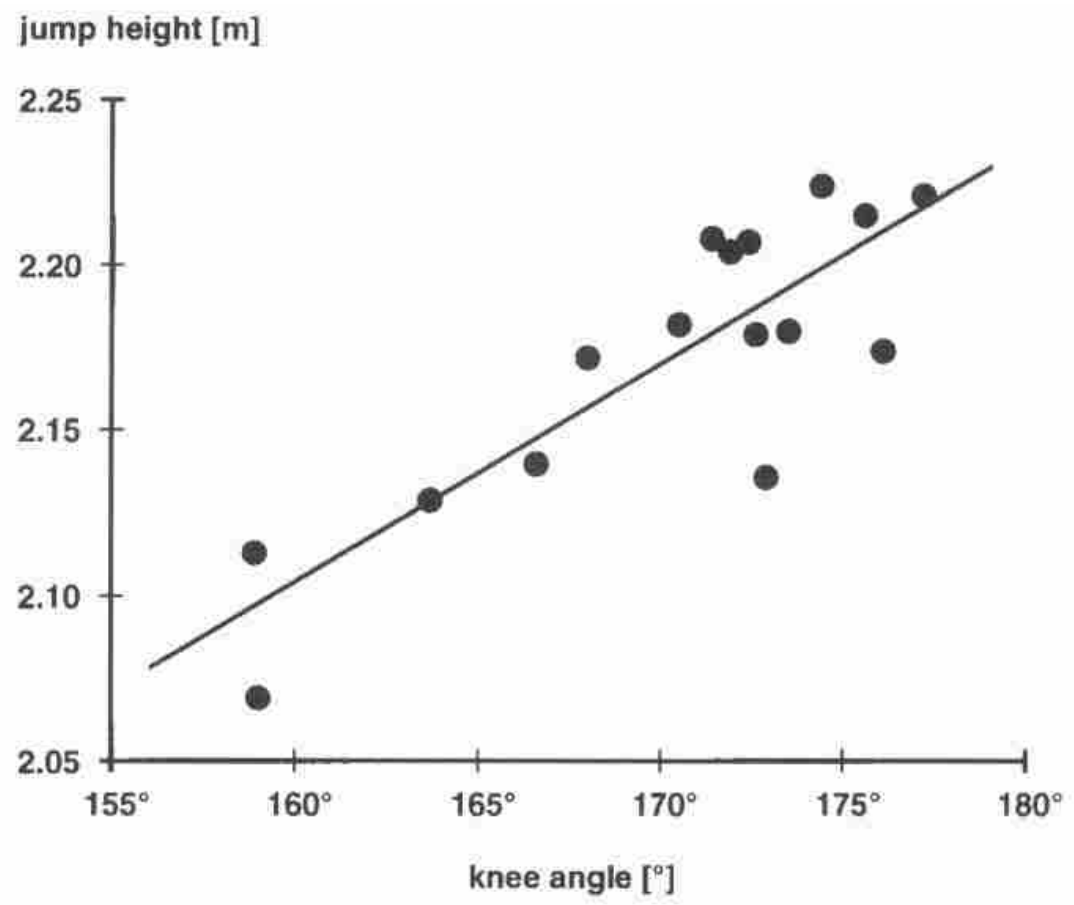

Figure 4-The influence of knee angle at touchdown on jump height.

In the previous regression equations it was implicitly assumed that the sole influence on jump height was the approach parameter included in the regression. Next the inter-relationships of the approach parameters were determined using linear correlation. There was a fairly strong and significant linear correlation between $\phi$ and $\mathrm{v}\left(\mathrm{r}^{2}=0.576, \mathrm{p}<0.001\right)$ and between $\phi$ and $\gamma\left(\mathrm{r}^{2}=\right.$ $0.550, \mathrm{p}<0.001)$. There was a very strong and significant linear correlation between $\mathrm{v}$ and $\gamma\left(\mathrm{r}^{2}=\right.$ 0.827, $\mathrm{p}<0.001)$. All of these correlations were positive so that faster approaches were associated with a straighter leg planted further away from the vertical.

The quadratic relationships between jump height and each of the approach parameters were reconsidered using residual values obtained by linearly detrending with respect to each of the approach parameters. For example h was linearly detrended with respect to $\phi$ using equation (2) so that:

(7) $\mathrm{h}_{\phi}=\mathrm{h}-(1.6127+0.01643 \phi)$

Similarly using equations (1) and (3):

(8) $\mathrm{h}_{\mathrm{v}}=\mathrm{h}-(1.6532+0.07864 \mathrm{v})$

(9) $\mathrm{h}_{\gamma}=\mathrm{h}-(1.0493+0.00659 \gamma)$

This gave rise to the following four equations:

(10) $\mathrm{h}_{\phi}=0.8940 \mathrm{v}_{\phi}-0.06390 \mathrm{v}_{\phi}^{2} \quad$ s.e. $=0.022 \mathrm{~m} \quad \mathrm{r}^{2}=0.550 \quad \mathrm{p}_{\mathrm{v}}=0.021 \quad \mathrm{p}_{\mathrm{v}^{2}}=0.030$

(11) $\mathrm{h}_{\mathrm{v}}=0.2234 \phi_{\mathrm{v}}-0.00331 \phi_{\mathrm{v}}^{2} \quad$ s.e. $=0.021 \mathrm{~m} \quad \mathrm{r}^{2}=0.403 \quad \mathrm{p}_{\phi}=0.010 \quad \mathrm{p}_{\phi^{2}}=0.011$

(12) $\mathrm{h}_{\gamma}=0.1681 \phi_{\gamma}-0.00247 \phi_{\gamma}^{2} \quad$ s.e. $=0.020 \mathrm{~m} \mathrm{r}^{2}=0.288 \quad \mathrm{p}_{\phi}=0.037 \quad \mathrm{p}_{\phi^{2}}=0.039$

(13) $\mathrm{h}_{\phi}=0.0924 \gamma_{\phi}-0.00026 \gamma_{\phi}^{2} \quad$ s.e. $=0.023 \mathrm{~m} \quad \mathrm{r}^{2}=0.528 \mathrm{p}_{\gamma}=0.216 \mathrm{p}_{\gamma^{2}}=0.245$

Note that there are no constant terms in equations (10) - (13) since the process of detrending centres the data so that the mean value of each detrended variable is zero and since a regression line or plane passes through the point corresponding to mean values. No residual values in $\mathrm{v}_{\gamma}$ or $\gamma_{\mathrm{v}}$ were used due to the strong linear correlation between $\mathrm{v}$ and $\gamma$. It can be seen that there were significant quadratic relationships between jump height and plant angle, particularly when linearly detrended for approach speed [smaller p values in equation (11) than in equation (12)], and between jump height and approach speed. However there was no significant quadratic relationship 
between jump height and knee angle $\left(\mathrm{p}_{\gamma^{2}}>0.2\right)$. The linear regression of $\mathrm{h}_{\phi}$ against $\gamma_{\phi}$ produced the following equation:
(14) $\mathrm{h}_{\phi}=0.00586 \gamma_{\phi}$
s.e. $=0.023 \mathrm{~m} \quad \mathrm{r}^{2}=0.478 \quad \mathrm{p}_{\gamma}=0.002$

The significant regressions in $\mathrm{v}_{\phi}$, $\phi_{\mathrm{v}}$ and $\gamma_{\phi}$ (equations (10), (11) and (14)) may be rewritten without the use of residual values using equations (7), (8) and similar equations for the detrended approach variables. For example:

(15) $\mathrm{v}_{\phi}=\mathrm{v}-(0.253+0.186 \phi)$

(16) $\mathrm{v}^{2}{ }_{\phi}=\mathrm{v}^{2}-(-39.517+2.445 \phi)$

Substituting for $\mathrm{h}_{\phi}, \mathrm{v}_{\phi}$ and $\mathrm{v}_{\phi}^{2}$ from equations (7), (15) and (16) in equation (10) gives:

(17) $\mathrm{h}=-1.139+0.89400 \mathrm{v}-0.06390 \mathrm{v}^{2}+0.00606 \phi \quad$ s.e. $=0.024 \mathrm{~m} \quad \mathrm{r}^{2}=0.761$

Similarly substituting for $h_{v}$ from (8) and expressions for $\phi_{v}$ and $\phi^{2}{ }_{v}$ in equation (11) leads

to:

(18) $\mathrm{h}=-2.089+0.22340 \phi-0.00331 \phi^{2}+0.07604 \mathrm{v} \quad$ s.e. $=0.023 \mathrm{~m} \quad \mathrm{r}^{2}=0.790$

Substituting for $\mathrm{h}_{\phi}$ from (7) and for an expression for $\gamma_{\phi}$ in equation (14) leads to:

(19) $\mathrm{h}=1.071+0.00586 \gamma+0.00304 \phi \quad$ s.e. $=0.025 \mathrm{~m} \mathrm{r} \mathrm{r}^{2}=0.723$

Adjusted jump height values $h_{a d j 1}, h_{a d j 2}, h_{a d j 3}$ were obtained by normalising the jump height with respect to the mean value of the approach parameter used in the linear detrending. Equations (17), (18) and (19) were re-written as:

(20) $\mathrm{h}_{\mathrm{adj} 1}=\mathrm{h}-0.00606\left(\phi-\phi_{\mathrm{av}}\right)=-1.139+0.00606 \phi_{\mathrm{av}}+0.89400 \mathrm{v}-0.06390 \mathrm{v}^{2}$

(21) $\mathrm{h}_{\mathrm{adj} 2}=\mathrm{h}-0.07604\left(\mathrm{v}-\mathrm{v}_{\mathrm{av}}\right)=-2.089+0.07604 \mathrm{v}_{\mathrm{av}}+0.22340 \phi-0.00331 \phi^{2}$

(22) $\mathrm{h}_{\mathrm{adj} 3}=\mathrm{h}-0.00304\left(\phi-\phi_{\mathrm{av}}\right)=1.071+0.00304 \phi_{\mathrm{av}}+0.00586 \gamma$

where $\mathrm{v}_{\mathrm{av}}=6.598 \mathrm{~m} \cdot \mathrm{s}^{-1}$ and $\phi_{\mathrm{av}}=34.05^{\circ}$ over the 16 jumps.

For each of the equations $(20)-(22)$ the $h_{\text {adj }}$ terms were calculated for each of the 16 jumps. The following regressions were then performed to examine the quadratic relationships between $\mathrm{h}$ and $\mathrm{v}$ and between $\mathrm{h}$ and $\phi$, and the linear relationship between $\mathrm{h}$ and $\gamma$. Note that equations (23) - (25) are equivalent to (20) -(22) and to (17) - (19).

(23) $\mathrm{h}_{\mathrm{adj} 1}=-0.933+0.89400 \mathrm{v}-0.06390 \mathrm{v}^{2} \quad$ s.e. $=0.023 \mathrm{~m} \quad \mathrm{r}^{2}=0.667$

$$
\mathrm{p}_{\mathrm{c}}=0.432 \mathrm{p}_{\mathrm{v}}=0.025 \mathrm{p}_{\mathrm{v}^{2}}=0.034
$$

(24) $\mathrm{h}_{\mathrm{adj} 2}=-1.587+0.22340 \phi-0.00331 \phi^{2} \quad$ s.e. $=0.022 \mathrm{~m} \mathrm{r} \mathrm{r}^{2}=0.405$

$\mathrm{p}_{\mathrm{c}}=0.238 \mathrm{p}_{\phi}=0.012 \mathrm{p}_{\phi^{2}}=0.013$

(25) $h_{\text {adj3 }}=1.174+0.00586 \gamma$

s.e. $=0.024 \mathrm{~m} \mathrm{r} \quad \mathrm{r}^{2}=0.671$

$\mathrm{p}_{\mathrm{c}}<0.001 \mathrm{p}_{\gamma}<0.001$

There were significant quadratic relationships between the adjusted jump height and approach speed and leg plant angle respectively (Figures $5 \& 6$ ). There was a significant linear relationship between the adjusted jump height and the knee angle at touchdown (Figure 7). 


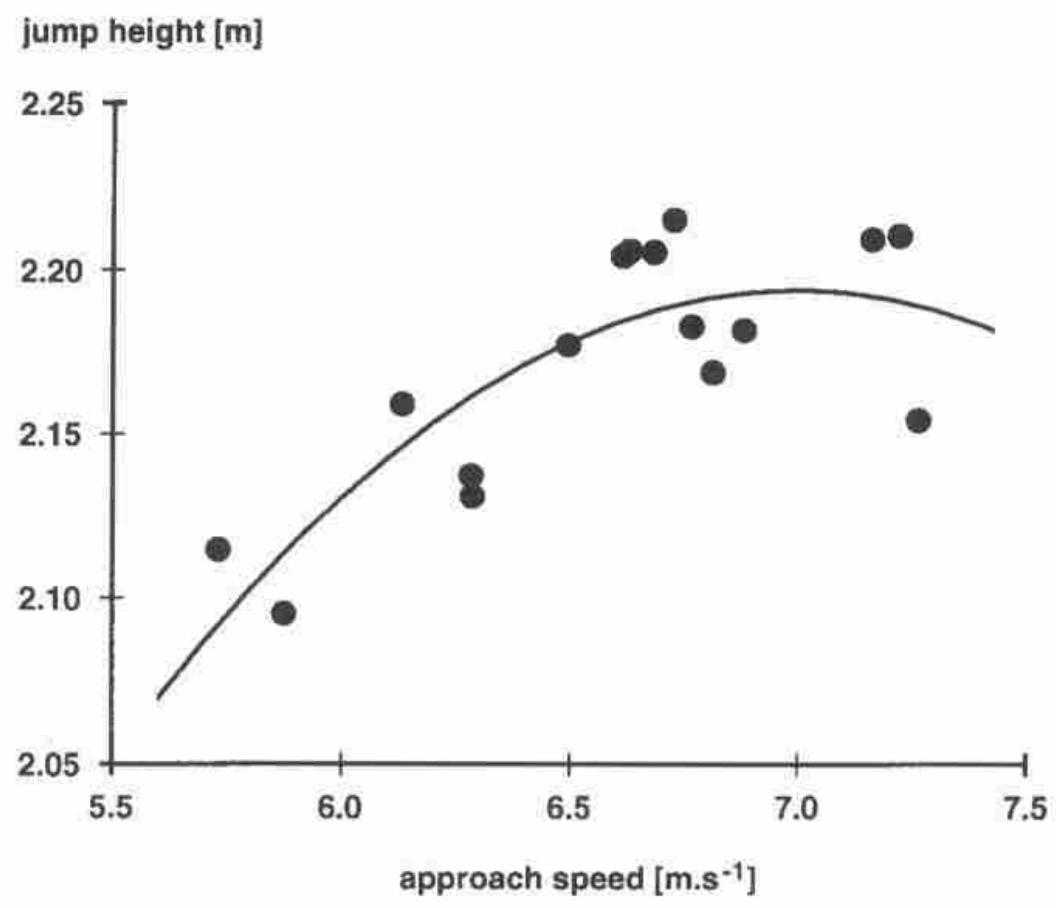

Figure 5-The quadratic relationship between jump height and approach speed when adjusted for leg plant angle.

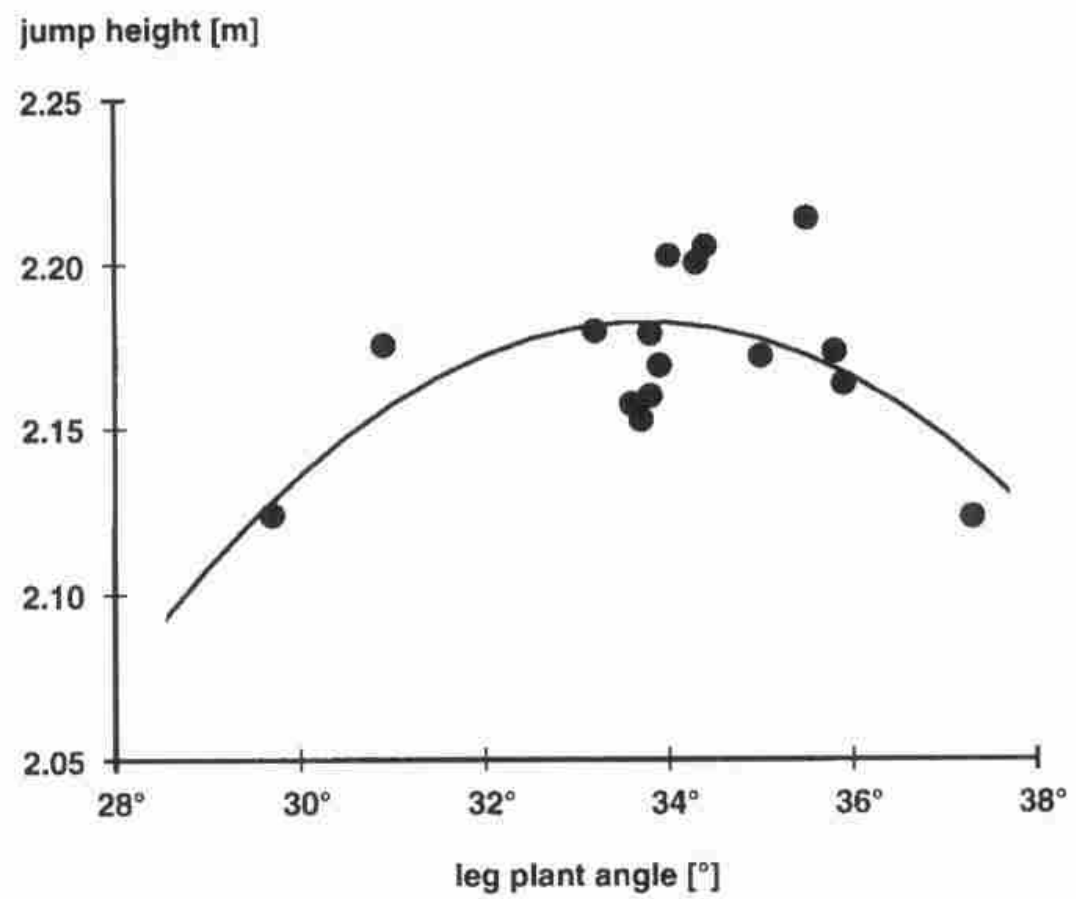

Figure 6 - The quadratic relationship between jump height and leg plant angle when adjusted for approach speed. 


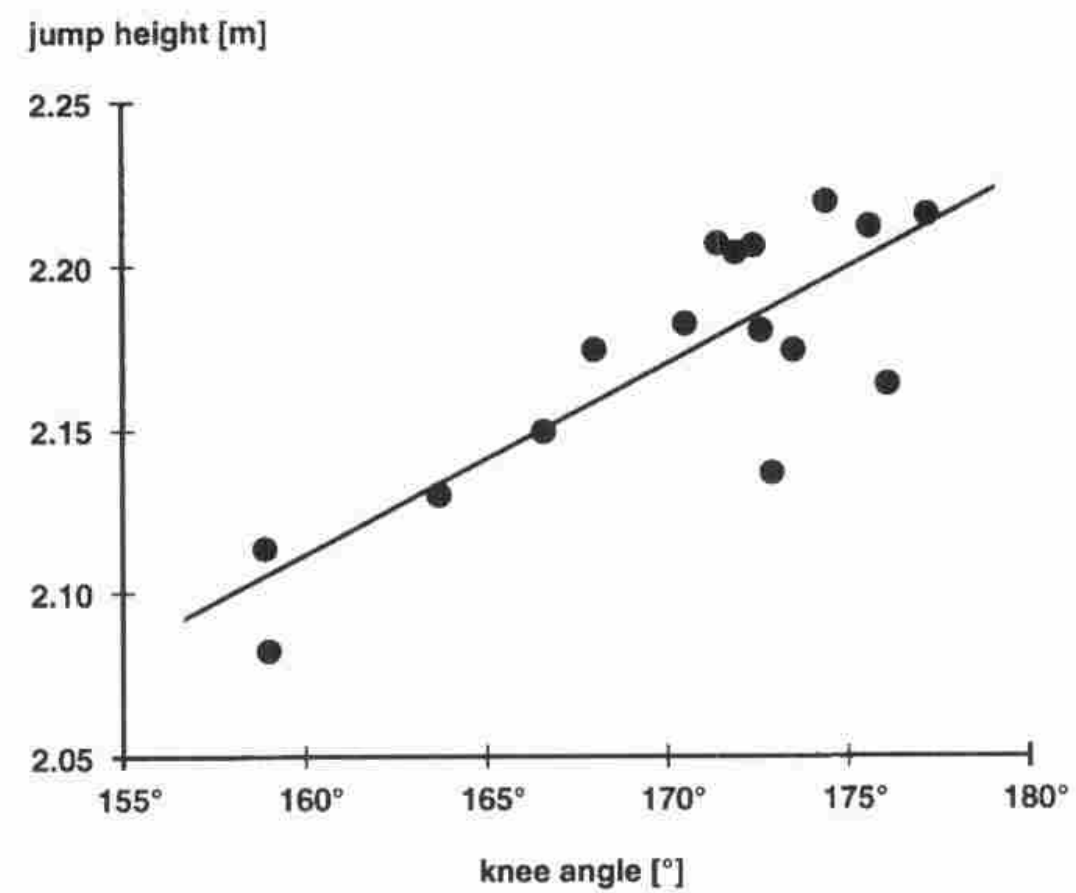

Figure 7 - The linear relationship between jump height and knee angle when adjusted for leg plant angle.

Equation (18), relating the jump height $\mathrm{h}$ to the approach speed $\mathrm{v}$ and the leg plant angle $\phi$, had a larger $r^{2}$ value than equations (17) and (19). Equation (18) was used to determine the predicted jump height $\mathrm{h}_{\text {pred }}$ for each of the 16 jumps, where :

(26) $\begin{aligned} \mathrm{h}_{\text {pred }}=-2.089 & +0.22340 \phi-0.00331 \phi^{2}+0.07604 \mathrm{v} \quad \text { s.e. }=0.023 \mathrm{~m} \mathrm{r}^{2}=0.790 \\ \mathrm{p}_{\mathrm{c}} & =0.151 \mathrm{p}_{\phi}=0.017 \quad \mathrm{p}_{\phi^{2}}=0.019 \mathrm{p}_{\mathrm{v}}=0.003\end{aligned}$

This equation was able to account for $79 \%$ of the observed variation in jump height over the 16 jumps analysed. Table 1 shows the recorded approach speed $v$, leg plant angle $\phi$ and knee angle $\gamma$ for each of the 16 jumps. Also shown are the predicted jump height $\mathrm{h}_{\text {pred }}$ calculated using equation (26) and the actual jump height $h_{\text {act }}$. Over the 16 jumps the standard deviation in $h_{\text {act }}$ was $0.044 \mathrm{~m}$. Figure 8 shows the relationship between $\mathrm{h}_{\text {pred }}$ and $\mathrm{h}_{\text {act }}$ and a linear function defined by $\mathrm{h}_{\text {pred }}=\mathrm{h}_{\text {act }}$. 
Table 1 Predcting jump height from approach parameters

\begin{tabular}{cccccc} 
trial & $v\left[\mathrm{~m} \cdot \mathrm{s}^{-1}\right]$ & $\phi\left[^{\circ}\right]$ & $\gamma\left[^{\circ}\right]$ & $\mathrm{h}_{\text {pred }}[\mathrm{m}]$ & $\mathrm{h}_{\text {act }}[\mathrm{m}]$ \\
\hline 01 & 5.731 & $33.8^{\circ}$ & $158.9^{\circ}$ & 2.116 & 2.113 \\
02 & 6.286 & $33.7^{\circ}$ & $163.7^{\circ}$ & 2.158 & 2.129 \\
03 & 6.496 & $33.2^{\circ}$ & $168.0^{\circ}$ & 2.173 & 2.172 \\
04 & 5.874 & $29.7^{\circ}$ & $159.0^{\circ}$ & 2.073 & 2.069 \\
05 & 6.283 & $33.8^{\circ}$ & $172.9^{\circ}$ & 2.158 & 2.136 \\
06 & 6.684 & $34.3^{\circ}$ & $172.4^{\circ}$ & 2.188 & 2.207 \\
07 & 6.616 & $34.0^{\circ}$ & $171.9^{\circ}$ & 2.183 & 2.204 \\
08 & 6.132 & $30.9^{\circ}$ & $166.6^{\circ}$ & 2.120 & 2.140 \\
09 & 6.631 & $34.4^{\circ}$ & $171.4^{\circ}$ & 2.183 & 2.208 \\
10 & 6.728 & $35.5^{\circ}$ & $174.4^{\circ}$ & 2.182 & 2.224 \\
11 & 7.223 & $35.8^{\circ}$ & $177.2^{\circ}$ & 2.216 & 2.221 \\
12 & 7.163 & $35.0^{\circ}$ & $175.6^{\circ}$ & 2.220 & 2.215 \\
13 & 7.264 & $37.3^{\circ}$ & $176.1^{\circ}$ & 2.191 & 2.174 \\
14 & 6.881 & $33.6^{\circ}$ & $172.6^{\circ}$ & 2.204 & 2.179 \\
15 & 6.766 & $33.9^{\circ}$ & $170.5^{\circ}$ & 2.195 & 2.182 \\
16 & 6.813 & $35.9^{\circ}$ & $173.5^{\circ}$ & 2.183 & 2.180 \\
\hline Mean & 6.598 & $34.1^{\circ}$ & $170.3^{\circ}$ & 2.171 & 2.172 \\
$S D$ & 0.450 & $1.8^{\circ}$ & $5.6^{\circ}$ & 0.039 & 0.044 \\
\hline
\end{tabular}

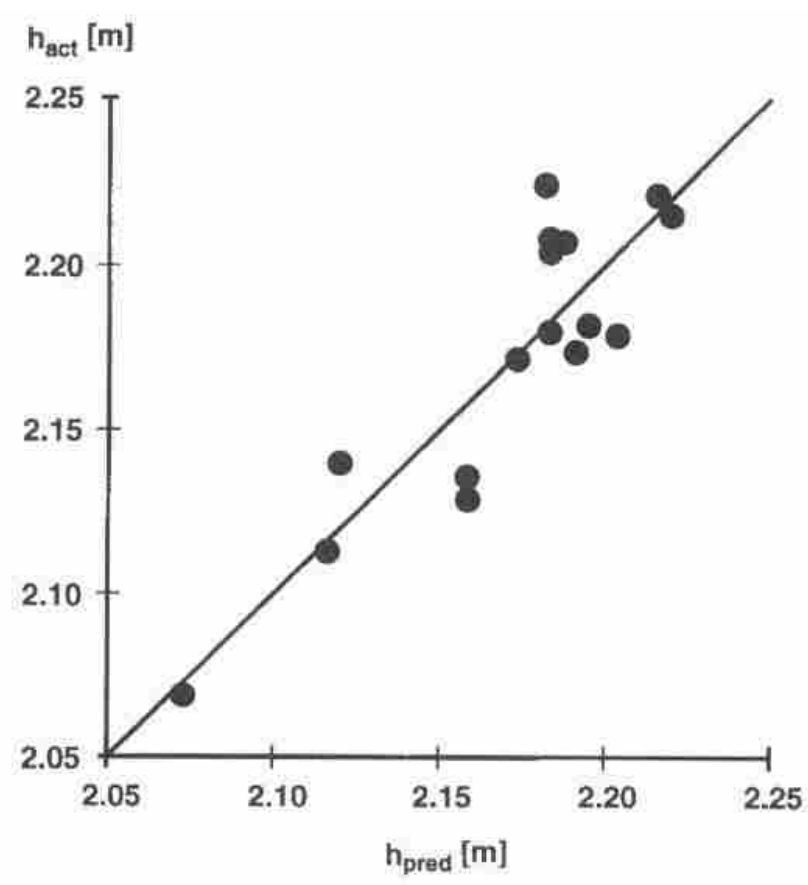

Figure 8 - The linear relationship between predicted and actual jump height.

Equation (23) expresses the relationship between $\mathrm{h}$ and $\mathrm{v}$ when the (linear) effects of $\phi$ have been removed. This quadratic relationship between $h_{\text {adj1 }}$ and $v$ yielded an optimum approach speed $v_{\text {opt }}$ of 7.00 m.s ${ }^{-1}$. Similarly the quadratic relationship (24) between $h_{\text {adj2 }}$ and $\phi$ produced an 
optimum leg plant angle $\phi_{\text {opt }}$ of $33.7^{\circ}$. Jump height $h_{\text {adj3 }}$ was shown by equation (25) to increase linearly with increasing knee angle $\gamma$ at touchdown. The maximum recorded knee angle $\gamma_{\max }$ was $177.2^{\circ}$.

In competition a full length approach is used and the ranges of values in each approach parameter are smaller than in the present study. The range in approach speed for the six full length approaches (trials 11-16 in Table 1) was $0.50 \mathrm{~m} . \mathrm{s}^{-1}$ compared with the overall range of $1.53 \mathrm{~m} . \mathrm{s}^{-1}$. The variation in jump height arising from the variation in each approach parameter $(\mathrm{v}, \phi, \gamma)$ was determined using the three regression equations for $h_{a d j 1}, h_{a d j}, h_{a d j 3}$ together with the approach parameter values of the six full length approaches. The results are shown in Table 2.

Table 2 The sensivity of jump height to changes in approach parameters

\begin{tabular}{cc} 
Range of approach parameter & Range of jump height $(\mathrm{m})$ \\
\hline$\Delta \mathrm{v}=0.50 \mathrm{~m} \cdot \mathrm{s}^{-1}$ & $\Delta \mathrm{h}_{\text {adf }}=0.004$ \\
$\Delta \phi=3.7^{\circ}$ & $\Delta \mathrm{h}_{\text {adj }}=0.041$ \\
$\Delta \gamma=6.7^{\circ}$ & $\Delta \mathrm{h}_{\text {adf }}=0.039$
\end{tabular}

\section{Discussion}

Hay (1985) stated that a high jumper may perform differently in training than in competition, with these differences evident in both the heights jumped and the technique used. In the present study a maximum jump height $\mathrm{h}$ of $2.22 \mathrm{~m}$ was achieved. The maximum recorded approach speed v was $7.26 \mathrm{~m} . \mathrm{s}^{-1}$. For the same athlete in competition Greig (1998) showed that jump height h varied from 2.19 - $2.25 \mathrm{~m}$ with a range in $\mathrm{v}$ of $6.95-7.29 \mathrm{~m} . \mathrm{s}^{-1}$. The data collected in the present study can therefore be considered to be representative of the athlete's competition technique.

Dapena et al. (1990) proposed that a high jumper cannot make many maximum effort jumps in a single day. In the present study 16 jumps were analysed. It is possible therefore that some of the jumps, or indeed all of the jumps, were not "all out" efforts. This situation would have two effects. Firstly there would be additional variance in the data and this would tend to obscure the relationships between variables. Secondly the maximum possible jump height would tend to be underestimated.

The non-linear theoretical relationships between jump height, approach speed and plant angle (Alexander, 1990) were confirmed by the experimental results in that (after linear detrending) jump height was significantly correlated with quadratic functions of approach speed and plant angle. The optimum approach speed and plant angle derived from these equations were $7.00 \mathrm{~m} . \mathrm{s}^{-1}$ and $33.7^{\circ}$ respectively. These are similar to the mean values of $7.02 \mathrm{~m} . \mathrm{s}^{-1}$ and $35.3^{\circ}$ for the six full length approach jumps. A significant linear relationship was obtained between jump height and knee angle at touchdown, indicating that jump height is maximised with a straight leg at touchdown. Again this result is in agreement with the theoretical finding of Alexander (1990). For the six full length approaches the knee angle ranged from $170.5^{\circ}$ to $177.2^{\circ}$.

The recorded approach speed and plant angle values were substituted into equation (26) containing terms in $\phi, \phi^{2}$ and $\mathrm{v}$ to calculate the predicted jump height for each of the 16 jumps. Since this regression equation was able to account for $79 \%$ of the observed variation in jump height over the 16 jumps it may be concluded that performance in high jumping is largely dependent on the approach. 
The sensitivity of jump height performance to the changes in each approach parameter was evaluated using the six full length approaches. Over the six jumps the jump height varied by $0.047 \mathrm{~m}$. The range in approach speed was shown to produce a range in jump height of only 0.004 $\mathrm{m}$ whereas the range in plant angle produced $0.041 \mathrm{~m}$ variation in jump height, and the knee angle range produced a variation of $0.039 \mathrm{~m}$ in jump height. Jump height was therefore shown to be most sensitive to changes in the leg plant angle and the knee angle at touchdown. The technical implications are that in order to maximise jump height this athlete should plant his leg at $34^{\circ}$ to the vertical with minimum knee flexion and approach at around $7 \mathrm{~ms}^{-1}$.

Whenever data are obtained on the performances of a single athlete there is always the possibility that the technique employed is very subject specific. Unless there are compelling theoretical reasons for believing that other athletes will behave similarly it is not possible to generalise the results of such a study. The technical implications described above arise from the quadratic relationships between jump height and approach velocity and between jump height and plant angle, and the linear relationship between jump height and knee angle. Simulation models of jumping have established that these relationships arise from the mechanics of the system rather than from individual idiosyncrasies of technique (Alexander, 1990; Greig, 1998; Yeadon, 1998). This gives some optimism for the expectation that similar results will be obtained for other elite high jumpers. The parameters of the quadratic relationships depend largely on the muscular characteristics of the athlete and these will vary with the height that the mass centre can be raised during flight (Dapena et al., 1990). High jumpers who are shorter than $1.96 \mathrm{~m}$ and have peak heights around $2.20 \mathrm{~m}$, or jumpers who are the same height as the subject of the present study but jump higher, may be expected to have optimum approach speeds in excess of $7 \mathrm{~m} . \mathrm{s}^{-1}$ and optimum leg plant angles greater than $34^{\circ}$. In all cases the optimum knee angle may be expected to be close to $180^{\circ}$.

\section{References}

Alexander, R.M. (1990). Optimum take-off techniques for high and long jumps. Philosophical Transactions of The Royal Society, B329, 3-10.

Dapena, J. (1988). Biomechanical analysis of the Fosbury Flop. Track Technique, 104, 3307-3317. Los Altos, CA: Tafnews Press.

Dapena, J., McDonald, C. \& Cappaert, J. (1990). A regression analysis of high jumping technique. International Journal of Sport Biomechanics, 6(3), 246-261.

Draper, N.R. and Smith, H. (1981). Applied regression analysis . New York: Wiley.

Greig, M.P. (1998). The influence of touchdown conditions on high jumping performance. Unpublished Master's dissertation. Loughborough University.

Hay, J.G. (1985). Issues in sports biomechanics. In S.M. Perren \& E. Schneider (Eds.), Biomechanics: Current interdisciplinary research (pp. 49-60). Dordrecht: Martinus Nijhoff.

Karara, H.M. (1980). Non-metric cameras. In K.B. Atkinson (Ed.), Developments in close range photogrammetry - 1. London: Applied Science Publishers.

Woicik, M. (1983). High jump, flop technique. Track and Field Quarterly Review, 83(4), 27-30.

Wood, G.A. and Jennings, L.S. (1979). On the use of spline functions in data smoothing. Journal of Biomechanics, 12, 477-479.

Yeadon, M.R. (1990a). The simulation of aerial movement - I: The determination of orientation angles from film data. Journal of Biomechanics, 23, 59-66.

Yeadon, M.R. (1990b). The simulation of aerial movement - II: A mathematical inertia model of the human body. Journal of Biomechanics, 23, 67-74. 
Yeadon, M.R. (1998). Computer simulation in sport biomechanics. In H.J. Riehle and M.M. Vieten (Eds.), Proceedings I, XVI International Symposium on Biomechanics in Sports (pp. 309-318). Zabel: International Society of Biomechanics in Sports.

Yeadon, M.R. and King, M.A. 1999. A method for synchronising digitised video data. Journal of Biomechanics, 32, 983-986. 
